\title{
A global analysis of zooplankton in natural and artificial fresh waters
}

\author{
Faye L. MERRIX-JONES, ${ }^{1}$ Stephen J. THACKERAY, ${ }^{2}$ Stephen J. ORMEROD ${ }^{1 *}$ \\ ${ }^{1}$ Cardiff School of Biosciences, Cardiff University, Cardiff CF10 3AX, Wales, UK; ${ }^{2}$ Centre for Ecology and Hydrology, Lancaster \\ Environment Centre, Library Avenue, Bailrigg, Lancaster LA1 4AP, England, UK. \\ *Corresponding author: ormerod@cardiff.ac.uk
}

\section{ABSTRACT}

Water-body size and location influence zooplankton diversity in freshwaters, but less is known about systematic variations in zooplankton community composition between natural and artificial waters on different continents. We used meta-analysis to assess how zooplankton in artificial water bodies across different biomes might differ from natural water bodies of similar size.

Among 79 lakes, ponds and reservoirs (11 artificial and 68 natural), proximity to other water bodies apparently increased species richness in all lake types, probably reflecting dispersal. However, richness did not differ systematically between natural and artificial water bodies of comparable size.

In contrast, community composition differed between artificial and natural waters after accounting for depth, productivity, longitude and conductivity, with models explaining up to 50\% of the overall variance at genus level. Leptodiaptomus, Chydorus, Cyclops, Acanthocyclops, Skistodiaptomus, Epischura, Limnocalanus, Senecella, Heterocope, Arctodiaptomus and Aglaodiaptomus all occurred more frequently in natural waters, whilst Thermocyclops, Moina and Epischura occurred more frequently in artificial lakes.

Rank-occurrence data revealed that Ceriodaphnia, Orthocyclops, Holopedium and Eucyclops were equitably distributed across water bodies of contrasting sizes, depths and climates. Other genera occurred under more specific conditions, typically where they had strong associations with natural lakes (e.g. Limnocalanus, Senecella, Heterocope, Arctodiaptomus and Aglaodiaptomus).

These results are among the first to illustrate systematic differences in zooplankton composition between natural and artificial lakes at a global scale. Potential explanations require further evidence, but might include provision for niche specialists in natural lakes versus reduced heterogeneity, management or disturbance effects in artificial lakes; and effects of lake age, stability and habitat naturalness in natural lakes. While zooplankton communities in natural lakes are well studied globally, more extensive data are required from artificial lakes.

Key words: zooplankton, species richness, community composition, meta-analysis.

Received: July 2012. Accepted: November 2012.

\section{INTRODUCTION}

Large-scale studies have shown that water body size, productivity and geographic location all influence zooplankton richness and community composition in lakes (e.g. Fryer, 1985; Sömmer et al., 1986; Dodson, 1992a, 1992b; Hessen et al., 2006). Island biogeography theory predicts a strong positive relationship between area and species richness, with larger habitats generally supporting a larger number of niches and increased immigration (MacArthur and Wilson, 1967). Increased zooplankton richness and compositional change, therefore, are expected with an increasing lake area (Dodson, 1992a; Shaw and Kelso, 1992; O'Brien et al., 2004; Karatayev et al., 2005; Dodson et al., 2009; Tavernini et al., 2009). Similarly, deeper water bodies support vertical segregation in a greater number of depth-related niches (Strøm, 1946), with several authors reporting changes in zooplankton diversity and composition with lake depth (Green and Vascotto, 1978; Dodson, 1992a; Korhola, 1999; Korhola et al., 2000; O’Brien et al., 2004; Amsinck et al., 2006; Tavernini et al., 2009).
Changes in food resource availability associated with primary productivity also affect zooplankton species richness and community structure (Dodson, 1992a; Dodson et al., 2009). Although the precise nature of these effects is debated, the generally accepted models are that richness and composition change unimodally (e.g. Dodson et al., 2000; Barnett and Beisner, 2007 ) or linearly with productivity (Chase and Ryberg, 2004; Hoffmann and Dodson, 2005), depending on the scale of observation (Chase and Ryberg, 2004) and the metric used to measure productivity (Thackeray, 2007).

In terrestrial habitats, geographic location is a further important determinant of species richness, with environmental predictability, increased solar energy, climatic variation and land area all expected to increase richness as latitude and/or altitude decrease (Gaston and Spicer, 2004). These patterns are reflected among freshwater zooplankton (Hobæk et al., 2002; Shurin et al., 2007; Tavernini et al., 2009). Community composition is highly dependent on geographic location (Shaw and Kelso, 1992; Dodson et al., 2009) and habitat connec- 
tivity (e.g. Forbes and Chase, 2002), with specialist species more likely to occur under more extreme climatic conditions (Halvorsen and Gullestad, 1976).

Whilst these large-scale studies provide a useful context for understanding influences on zooplankton species diversity among natural lakes on single continents, few studies have considered the extent to which zooplankton in artificial lakes follow the same trend. Dodson (1992a) considered the effect of lake size and depth on zooplankton species richness, but differences between artificial and natural lakes were not resolved. This lack of specific assessment is surprising, since artificial water bodies differ from natural water bodies not only in their age, but also hydrological regimes, morphometric character and degree of stability caused by human influence and management. All of these may be expected to influence pelagic zooplankton communities strongly.

Although it is difficult to predict accurately the ultimate biological character of new water bodies (Baxter and Glaude, 1980), long-term fluctuations in zooplankton communities following a water body's construction have been documented (Holland and Jenkins, 1998; De Mérona et al., 2001). Investigation into the potential differences in zooplankton communities between natural and artificial lakes could provide an important insight into ecosystem-wide variations, which in turn could inform management needs.

Here, we use meta-analysis (Osenberg et al., 1999) to make quantitative comparisons of well-studied lakes, using existing published data to obtain a global perspective of zooplankton communities in natural and artificial water bodies. Such analysis is useful in overcoming the challenges involved in collecting first-hand data from lakes over a wide geographical range and can increase statistical power by considering a larger number of lakes and studies, reducing the impact of any uncertainties associated with individual studies.

Our aim was to identify potential drivers of broadscale patterns in zooplankton community composition and richness among world lakes, and to assess whether artificial and natural water bodies support different zooplankton communities. Two hypotheses were tested. Firstly, that zooplankton taxon richness and community composition reflect water body morphometry. Specifically, characteristics related to lake size and geographical location are expected to predict taxon richness and community structure. Secondly, that artificial water bodies, such as man-made reservoirs and impoundments, exhibit different morphometric characteristics to naturally formed lakes. Natural and artificial lakes also differ in origins and management, and zooplankton taxon richness and community composition are also expected to differ.

\section{METHODS}

\section{Data sources}

This work was based on a literature search of studies on freshwater zooplankton in world lakes, reservoirs and ponds using the online database ISI Web of Science (http://wok.mimas.ac.uk) with the initial key words: zooplankton; species; freshwater; and either lake, pond or reservoir. Data were obtained from either the primary literature or associated supplementary material. Where possible, information was gathered for each water body on the number of pelagic crustacean zooplankton species; surface area $\left(\mathrm{m}^{2}\right)$; residence time (days); maximum and mean depth $(\mathrm{m})$; conductivity $(\mu \mathrm{S})$; primary production $\left(\mathrm{mgCm}^{-2} \mathrm{day}^{-1}\right)$; surface elevation ( $\mathrm{m}$ above sea level); latitude $\left({ }^{\circ} \mathrm{N}\right)$; longitude $\left({ }^{\circ} \mathrm{W}\right)$; distance to the nearest standing water body, visible on a 1:250,000 scale map $(\mathrm{km})$; and the number of lentic freshwater bodies in a $20 \mathrm{~km}$ radius. Any man-made water bodies were considered artificial. Other ecological factors, such as the presence or absence of fish and specific lake chemistry, are recognised as being important, but data were not available for all of the water bodies included in analysis.

\section{Study selection}

Data from natural and artificial water bodies, of various size, morphology and hydrological regime, from a range of latitudes and longitudes, were considered provided that zooplankton species lists were recorded over at least two years and in different seasons to minimise inter-annual and inter-seasonal variations in community composition (Dodson, 1992a). Only pelagic zooplankton was considered in species lists, excluding all littoral and benthic species. This is consistent with an earlier study by Dodson (1992a), who excluded all Scapholeberidae, all Sididae except $D i$ aphanosoma, all chydoridae except Chydorus sphaericus, all Macrothricidae, and all species of Simocephalus, Polyphemus, Macrocyclops, Ectocyclops, Megacyclops, Paracyclops, Microcyclops and Ergasilus.

Since zooplankton species were identified by numerous researchers, lists of genera were used for community analysis in an attempt to reduce the impact of inconsistencies or local variations in taxonomy. The genus data took the form of presence-absence.

\section{Statistical analysis}

To examine correlates of community composition, data on zooplankton genera from studied water bodies were first ordinated using Detrended Correspondence Analysis (DCA), chosen because of the large number of zero values in presence-absence data, the unimodal nature of the data, and the need to generate ordination axes unconstrained by environmental variables (Speckman et al., 
2005). No weighting was applied to individual genera. Regression analysis of DCA scores, as well as species richness, was carried out against all environmental variables $[\log (n+1)$ transformed to reduce the influence of outliers] in order to identify correlates with zooplankton species richness and community composition, along with $95 \%$ confidence and prediction intervals. Maximum depth was chosen as a representative depth variable, since mean and maximum depth were highly correlated.

Typically in ecological studies, multicollinearity occurs among potential explanatory variables making it difficult to partition the effects of single factors on species richness and community composition. To overcome this, general linear model analysis of covariance (ANCOVA) was used to determine whether zooplankton communities differed significantly between artificial and natural water bodies whilst controlling for variance in the data due to other correlates. Potential covariates were first identified from results of the regression analysis. Since ANCOVA assumes parallelism to ensure that the comparison of $y$ values is independent of the $\mathrm{x}$ values, regression gradients of each were tested for parallelism and transformed where necessary (Riggs et al., 2008). The ANCOVA models were constructed by first including all variables determined to be significant from individual linear regressions. Non-significant variables were then removed until the model included only significant variables.

To investigate zooplankton community composition further among different groups of water bodies, Two-way Indication Species Analysis (TWINSPAN) (Hill and Šmilauer, 2005), using five equally cut levels, was carried out on percentage occurrence data in order to classify zooplankton genera into those that commonly co-occurred in the different water bodies. Zooplankton genus rank-occurrence plots were constructed using mean occurrence to account for differences in number of water bodies between groups, and chi-squared $\left(\chi^{2}\right)$ tests were carried out to test whether their distributions differed significantly from random among artificial and natural water bodies.

\section{RESULTS}

A total of 106 lakes, reservoirs and ponds was identified from the literature for which data existed on pelagic crustacean species richness. Data on 65 of these were obtained from Dodson's (1992a) study on north American lakes. Full species lists were available for 79 of the 106 water bodies and of these 79 water bodies, 11 were artificial. A full list is provided by Merrix (2009).

\section{Correlates of zooplankton species richness and composition}

Interestingly, results differed for species richness and composition. As expected, species richness increased with increasing surface area, depth and number of lentic water bodies in a $20 \mathrm{~km}$ radius, but decreased with increasing distance to the nearest water body (Fig. 1). Ordination using DCA showed that DCA axis 1 (DCA1) score decreased with increasing depth, elevation and primary productivity (Fig. 2), but increased with latitude and longitude, consistent with the low scores of the predominantly tropical Thermocyclops genus and high scores of Limnocalanus and Diaptomus, tolerant of low temperatures (Gurney, 1933a, b). Other genera scoring highly on DCA1 included Heterocope, Chydorus and Eurytemora, with Eudiaptomus, Moina, Diaphanosoma, Arctodiaptomus and Tropocyclops having low scores. Detrended Correspondence Analysis axis 2 (DCA2) scores declined with depth and primary productivity (Fig. 3), consistent with high scoring Moina species often reported in small ponds and puddles (Fig. 4b). Detrended Correspondence Analysis axis 2 score increased with increasing isolation and conductivity, consistent with species of the low scoring Holopedium genus (Fig. 4b), which includes species with a preference for soft waters (Scourfield and Harding, 1994). Other high scoring genera on DCA2 included Arctodiaptomus, Eucyclops and Acanthocyclops, while low scoring taxa included Orthocyclops, Leptodiaptomus, Skistodiaptomus, Senecella and Epischura.

Two-way Indication Species Analysis identified four groups of water bodies, differing in physical and chemical characteristics (Fig. 5). Group 1 generally contained large, deep, tropical water bodies, while group 4 water bodies were smallest and most isolated. Groups 2 and 3 were made up of mainly intermediate sized water bodies and contrasted in primary production, with group 2 water bodies being more eutrophic than those in group 3 and supporting greater species richness (Fig. 6). In addition, zooplankton community composition, indicated by DCA axes scores, also differed between TWINSPAN groups (Fig. 6).

\section{Natural $v s$ artificial water bodies}

General linear model ANCOVA revealed that the number of water bodies in a $20 \mathrm{~km}$ radius was a more important covariate of species richness than knowing whether a water body was artificial or natural, explaining $33.21 \%$ of the variance in species richness (Fig. 7). Similarly, there was no difference in DCA axis 2 scores between artificial and natural water bodies. Conductivity was the only significant covariate, explaining $59.78 \%$ of the variance in DCA2. Conversely, DCA axis 1 scores differed significantly between artificial and natural water bodies when accounting for variance caused by differences in depth, primary productivity and longitude (Figs. 2 and $4 a$ ). Together, these variables explained $47.7 \%$ of the variation in DCA1.

Rank-occurrence plots revealed that several zooplankton taxa occurred relatively equitably among the four 

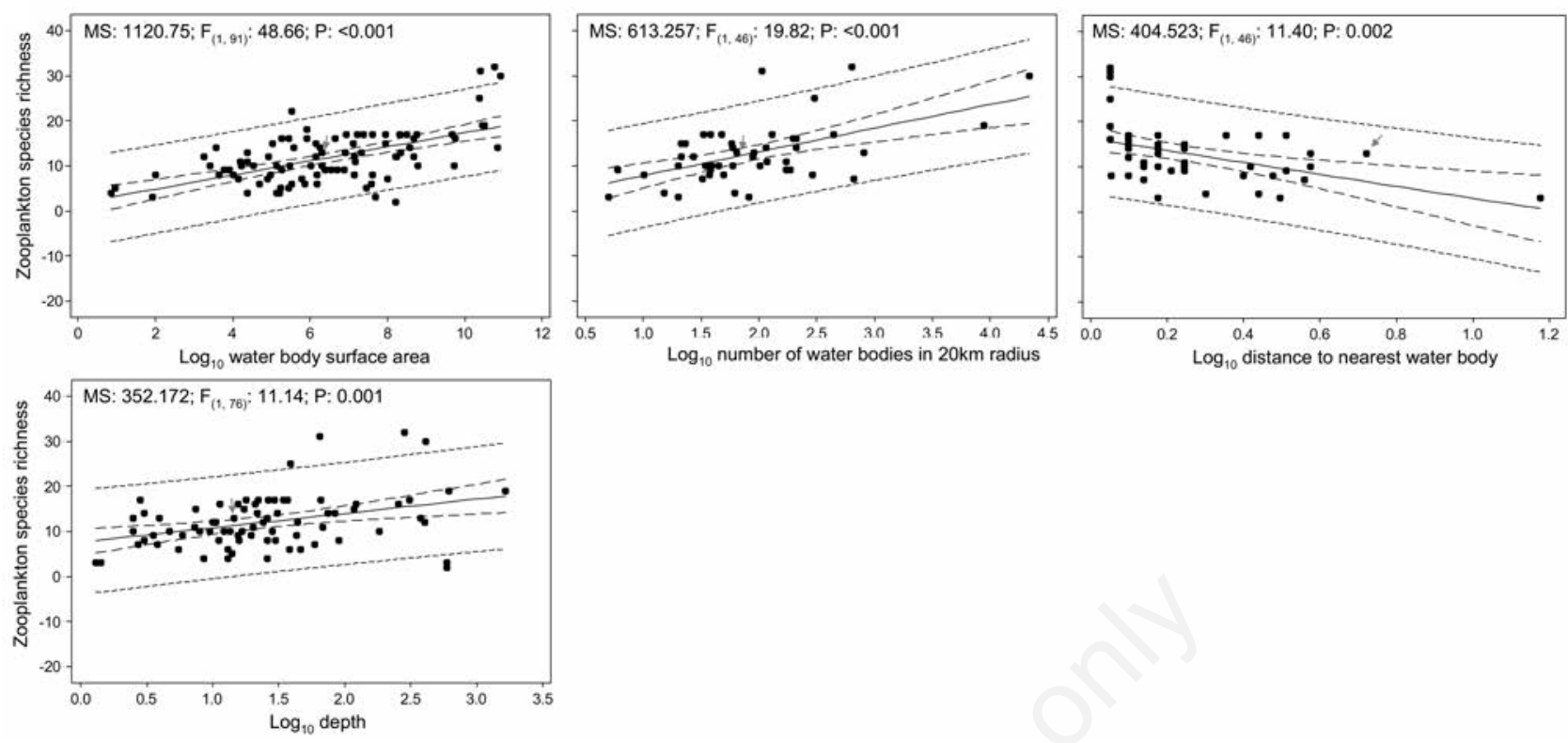

Fig. 1. Regression plots zooplankton species richness with characteristics of water bodies, showing $95 \%$ confidence intervals (-- -) and $95 \%$ prediction intervals (---). Labels used are: MS, i.e. mean sum of squares, and F, i.e. test value with associated degrees of freedom.
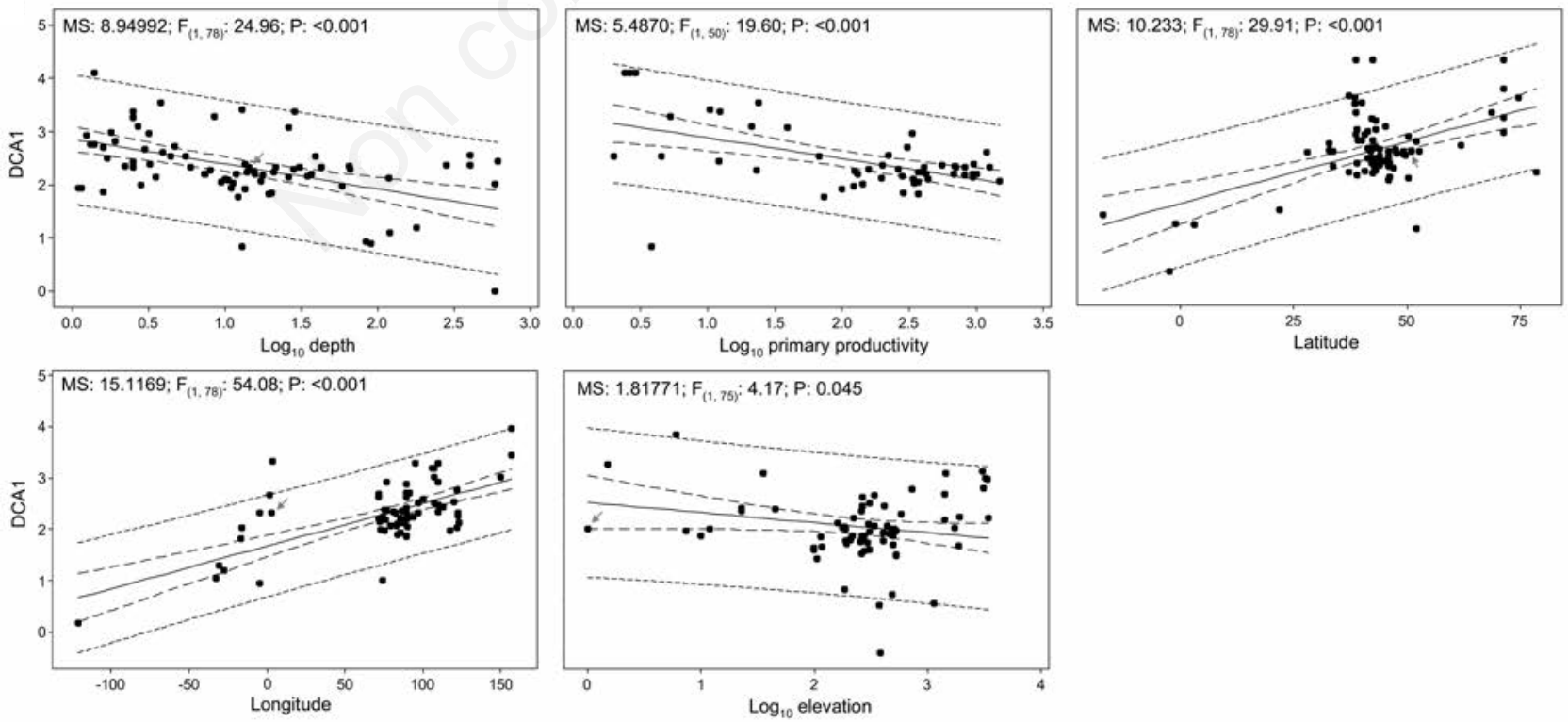

Fig. 2. Regression plots of DCA axis 1 scores with characteristics of water bodies, showing $95 \%$ confidence intervals (-- -) and $95 \%$ prediction intervals (---). Detrended Correspondence Analysis axes scores were obtained from ordination of zooplankton genera data from 79 lakes. Labels used are: MS, i.e. mean sum of squares, and F, i.e. test value with associated degrees of freedom. 
TWINPSAN groups and among natural and artificial water bodies (Fig 8a). Ceriodaphnia showed a particularly equitable occurrence among groups of water bodies, with a $26: 27: 25: 22 \%$ split between TWINSPAN groups $1,2,3$, and 4 and a 51:49\% split between natural and artificial water bodies. Orthocyclops, Holopedium and Eucyclops showed similar patterns of occurrence between artificial and natural water bodies. However, some genera appeared to be more specialised. Thermocyclops occurred only in the tropical water bodies of group 1, whilst Leptodora, Skistodiaptomus, Orthocyclops, Senecella and Aglaodiaptomus were only recorded in the more productive group 2 water bodies. Heterocope only occurred in group 3 water bodies and Arctodiaptomus was present only in the smaller, more isolated water bodies of group 4 (Fig. 8b). Limnocalanus, Senecella, Heterocope, Arctodiaptomus and Aglaodiaptomus appeared to be the most specialised genera among artificial and natural water bodies, occurring exclusively in natural lakes (Fig. 8c). As well as these five genera, Leptodiaptomus, Chydorus, $C y$ clops, Acanthocyclops, Skistodiaptomus and Epischura species also had significantly higher occurrence in natural lakes, as revealed with $\chi^{2}$ tests (Tab. 1). Conversely, Thermocyclops, Moina and Eudiaptomus species occurred significantly more often in artificial water bodies.

\section{DISCUSSION}

The aim of this meta-analysis was to identify potential influences on zooplankton community composition and richness among lakes around the world and assess whether artificial and natural water bodies support different zooplankton communities. There are very few studies comparing zooplankton community composition, particularly among inter-continental lakes over a range of latitudes, longitudes and altitudes simultaneously. A major problem encountered in undertaking such analysis is the risk of inconsistencies in the taxonomic identification of zooplankton species. In the present study, the slight reduction in resolution incurred when grouping zooplankton by genera was considered an appropriate trade-off to account for these inconsistencies.

Two hypotheses were tested. Firstly that broad-scale patterns in richness and composition will be related to gradients in lake morphometry, productivity and location. Secondly, when accounting for these drivers, there will be a discernible difference in richness and composition between natural and artificial waterbodies. The first hypothesis was supported, with several variables correlating with both richness and composition. This did not lead to differences in species richness between water body types, but as expected community composition, quantified using
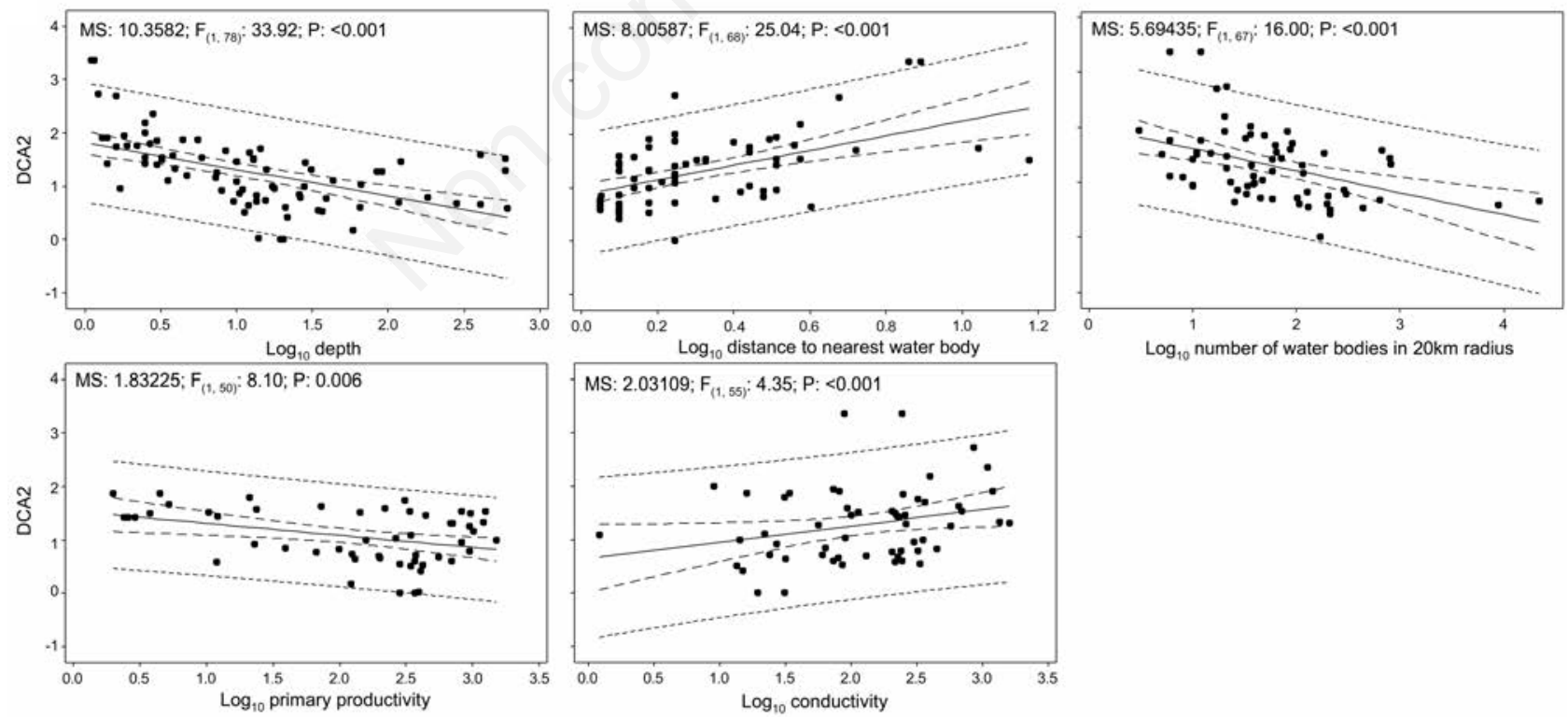

$\log _{10}$ number of water bodies in $20 \mathrm{~km}$ radius

Fig. 3. Regression plots DCA axis 2 scores with characteristics of water bodies, showing $95 \%$ confidence intervals (---) and $95 \%$ prediction intervals (---). Detrended Correspondence Analysis axes scores were obtained from ordination of zooplankton genera data from 79 lakes. Labels used are: MS, i.e. mean sum of squares, and F, i.e. test value with associated degrees of freedom. Grey arrows indicate the position of Cardiff bay where applicable. 
DCA axes scores, differed between artificial and natural water bodies after accounting for depth, productivity, longitude or conductivity.

\section{Correlates of zooplankton species richness and composition}

Previous studies have shown that factors related to water body size and geographic location are important influences on zooplankton species richness and community composition (Tab. 2). Central to these postulated effects is the theory of island biogeography and the importance of habitat size, dispersal and species interactions in shaping lentic zooplankton communities (Hobæk et al., 2002). In the present study, and in agreement with Dodson (1992a), the number of water bodies in a $20 \mathrm{~km}$ radius was found to be a significant predictor of zooplankton species richness (Fig. 1). This agreement is unsurprising, since a large number of the water bodies for which this information was available were included in Dodson's (1992a) study and is probably due the increased likelihood of immigration from regional source populations. More interesting in the present context is how the natural or artificial nature of water bodies affected richness or community composition (see below).

Among the water bodies studied, zooplankton community composition was linked with water body depth, productivity and conductivity, in concurrence with previous studies (Tab. 2). It is generally accepted that deeper lakes support a larger number of vertical niches, allowing greater niche separation of competing species (Strøm, 1946). Dodson et al. (2009) documented a shift in community composition from small to large zooplankton species with increasing productivity and conductivity of temperate lakes in Northern Wisconsin (USA). The unimodal productivityzooplankton diversity model (e.g. Dodson et al., 2000; Barnett and Beisner, 2007) suggests that there is an optimum productivity at which zooplankton communities are most diverse. Above this, changes in phytoplankton composition associated with eutrophication lead to the development of zooplankton communities better adapted for dominance by blue-green algae species (Richman and Dodson, 1983; Smith, 1983; Gliwicz and Lampert, 1990; Watson et al., 1997). The present study revealed no such relationship with species richness but a linear relationship was apparent between productivity and community composition represented by DCA axes (Figs. 2 and 3).

Whilst zooplankton species richness was correlated with water body surface area, surprisingly there appeared to be no effect on community composition. Even more surprisingly, when controlling for covariates, surface area did not significantly explain any variation in species richness (Fig. 7). This result is in contrast with numerous other studies, which have identified positive relationships between surface area and both richness and composition (Tab. 2). Furthermore, it is in contrast to the predictions of the island
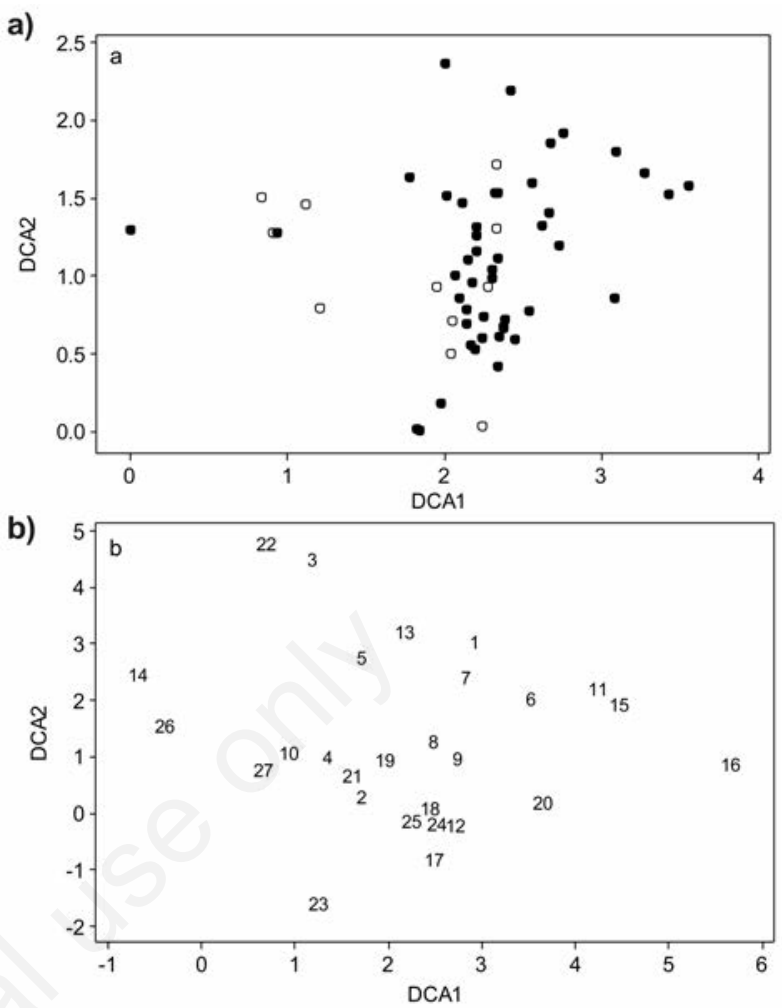

Fig. 4. Water body (a) and genus (b) axes scores from DCA ordination of zooplankton genera recorded in 79 world lakes. a) Detrended Correspondence Analysis axis 1 scores differ significantly between artificial $(\circ)$ and natural $(\bullet)$ water bodies (ANCOVA, $\left.\mathrm{F}_{(1,35)}=6.62 ; \mathrm{P}=0.017\right)$. b) Genera are labelled as follows: 1, Acanthocyclops; 2, Aglaodiaptomus; 3, Arctodiaptomus; 4, Bosmina; 5, Ceriodaphnia; 6, Chydorus; 7, Cyclops; 8, Daphnia; 9, Diacyclops; 10, Diaphanosoma; 11, Diaptomus; 12, Epischura; 13, Eucyclops; 14, Eudiaptomus; 15, Eurytemora; 16, Heterocope; 17, Holopedium; 18, Leptodiaptomus; 19, Leptodora; 20, Limnocalanus; 21, Mesocyclops; 22, Moina; 23, Orthocyclops; 24, Senecella; 25, Skistodiaptomus; 26, Thermocyclops; 27, Tropocyclops.

Tab. 1. Results from $\chi^{2-}$ tests showing zooplankton genera with occurrence significantly different from random among artificial and natural water bodies.

\begin{tabular}{lccr}
\hline & Genus & $\chi^{2}$ & $\mathrm{P}$ \\
\hline Natural & Leptodiaptomus & 12.76 & $<0.001$ \\
& Chydorus & 8.05 & 0.005 \\
& Cyclops & 12.03 & $<0.001$ \\
& Acanthocyclops & 26.41 & $<0.001$ \\
& Skistodiaptomus & 24.34 & $<0.001$ \\
Epischura & 5.48 & 0.019 \\
& Limnocalanus & 50.00 & $<0.001$ \\
& Senecella & 50.00 & $<0.001$ \\
& Heterocope & 50.00 & $<0.001$ \\
& Arctodiaptomus & 50.00 & $<0.001$ \\
& Aglaodiaptomus & 50.00 & $<0.001$ \\
& & & \\
Artificial & Thermocyclops & 23.43 & $<0.001$ \\
& Moina & 19.26 & $<0.001$ \\
& Eudiaptomus & 6.56 & 0.010 \\
\hline
\end{tabular}


biogeography theory that as area increases, there is a higher probability of immigration and a larger number of available niches allowing more species to coexist (MacArthur and Wilson, 1967). In a study of Norwegian lakes, however, Hessen et al. (2006) also found that water body size had no significant positive effect on zooplankton species richness and in fact showed a weakly negative relationship. Instead, these authors found intrinsic factors such as primary productivity, linked with zooplankton community composition in the present study, and fish community structure were most important, exerting bottom-up and top-down control of the zooplankton community, respectively.

Rank occurrence data revealed that among the water bodies studied, the genus Ceriodaphnia showed a cosmopolitan distribution among TWINSPAN groups of water bodies, characteristic of generalist taxa. This suggests that Ceriodaphnia species are found in a range of water bodies of different sizes, depths, climates and degrees of isolation. Conversely, a number of genera appeared to be specialists, each occurring in only one TWINSPAN group. Thermocyclops was only recorded in the tropical water bodies of group 1; Leptodora, Skistodiaptomus, Orthocyclops, Senecella and Aglaodiaptomus only in the more productive water bodies of group 2; Heterocope only in group 3; and Arctodiaptomus only in the more isolated water bodies of group 4 .
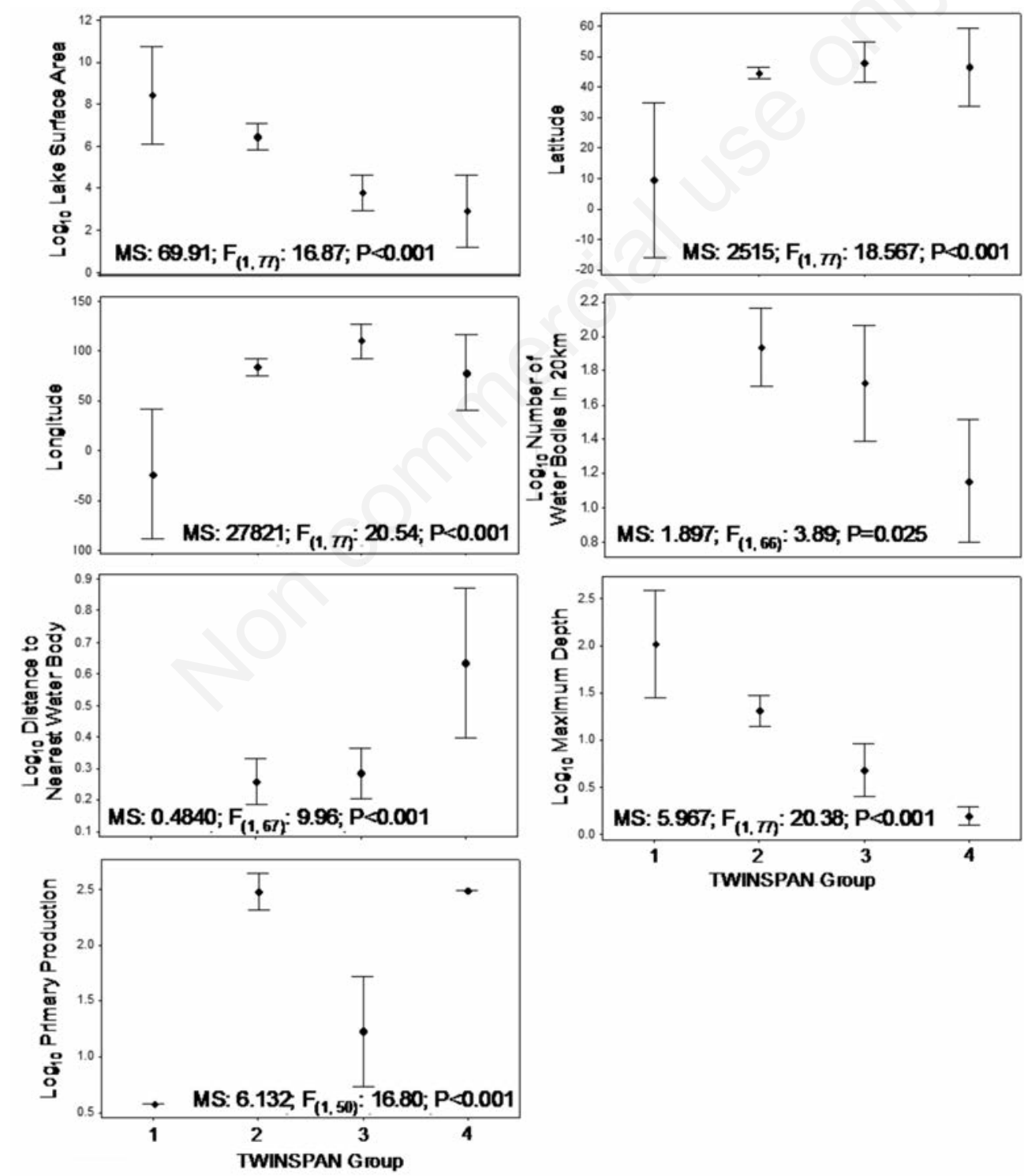

Fig. 5. Groups identified using TWINSPAN of 79 well-studied world lakes, with variations in lake characteristics among groups, identified using ANOVA. MS, mean sum of squares; F, test value with associated degrees of freedom. 


\section{Natural vs artificial water bodies}

Analysis of covariance revealed that longitude was linked with zooplankton community composition regardless of whether the water bodies were artificial or naturally formed. While this may be an artefact of the larger representation of north American lakes in the study, among which Dodson (1992a) reported that changes in species richness were independent of longitude, there are very few studies that have investigated inter-continental longitudinal gradients in zooplankton communities.

Zooplankton community composition, represented by the first DCA ordination axis, differed between artificial and natural water bodies, as well as with within-lake characteristics depth, primary productivity and longitude. Artificial water bodies are geologically very young, compared with natural lakes formed over thousands of years. Whilst this difference in age may be expected to produce markedly different zooplankton communities, there is no evidence of this being the case. Dodson et al. (2006), for example, found that water body age had no effect on zooplankton species richness in a study of lakes between 3 and 9500 years old. How rapidly zooplankton communities become established in a water body is unknown and there are few studies investigating the acquisition of zooplankton communities in artificial water bodies. Zooplankton communities, however, may never reach equilibrium due to regular small-scale disturbances (Matsumura-Tundisi and Tundisi, 2002; Scheffer et al., 2003), suggesting that only a short time following initial colonisation, there may be no discernible impact of water body age.

The nature of water body construction, often for the provision of human services or amenity, commonly necessitates maintenance of good water quality in artificial water bodies. Management practices such as artificial destratification and biomanipulation of fish communities are often employed to reduce the undesirable impacts of eutrophication, such as cyanobacterial blooms, reduced oxygen concentration and increased turbidity (Cowell et al., 1987; Hawkins and Griffiths, 1993; Lewis et al., 2003; Antenucci et al., 2005; Becker et al., 2006; Burford and O'Donohue, 2006). Changes in zooplankton composition from large to small bodied cladocera have been observed during aeration (e.g. Cowell et al., 1987), but there are few other studies documenting the effect of this remediation method on zooplankton communities. Biomanipulation relies on the alteration of zooplankton community structure for the control of algae. Such management practices are a probable cause of variation in zooplankton communities between artificial and natural water bodies (e.g. Brooks and Dodson, 1965; Cowell et al., 1987; Hessen et al., 1995; Shurin, 2001; Shurin and Allen, 2001) and therefore likely to produce the observed differences in the present study.

The variance in DCA axis 1 explained by productivity, depth, longitude and water body type was a relatively modest $47.7 \%$. This suggests the importance of some unmeasured factors or stochasticity in structuring zooplank-
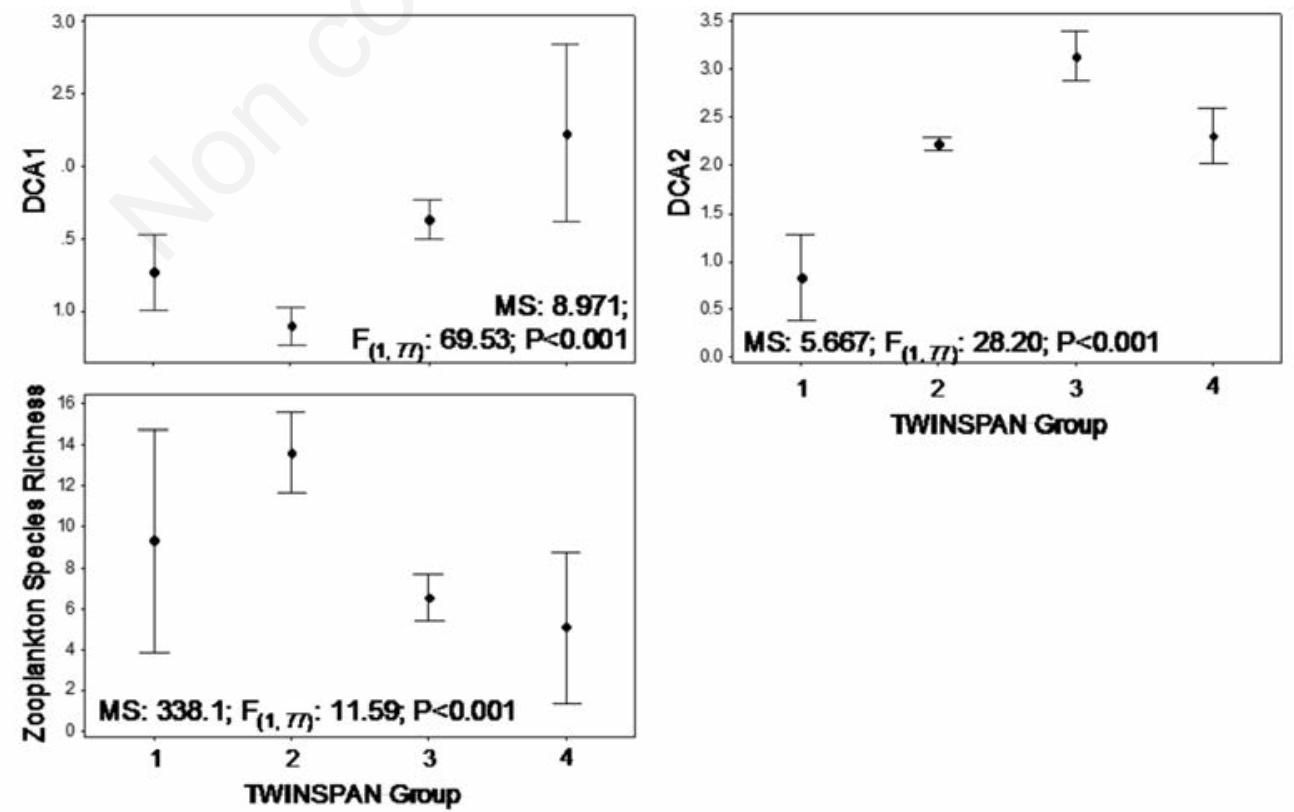

TWINSPAN Group

Fig. 6. Groups identified using TWINSPAN of 79 well-studied world lakes, with variations in zooplankton community composition, represented by DCA axes, and species richness, identified using ANOVA. MS, mean sum of squares; F, test value with associated degrees of freedom. 
ton communities among the studied water bodies and could represent differences in sampling methods between water bodies. Similarly, the variance explained in species richness by significant factors was only $33.2 \%$. Previous studies have shown biotic interactions such as predation, competition and dispersal to be important drivers of zooplankton community structure (Hobæk et al., 2002), none of which could be quantified in the present study. The importance of fish predation in structuring zooplankton communities was examined by Brooks and Dodson (1965), who proposed the Size Efficiency Hypothesis to explain the mechanism behind observed changes to zooplankton communities under different predation regimes. This hy-
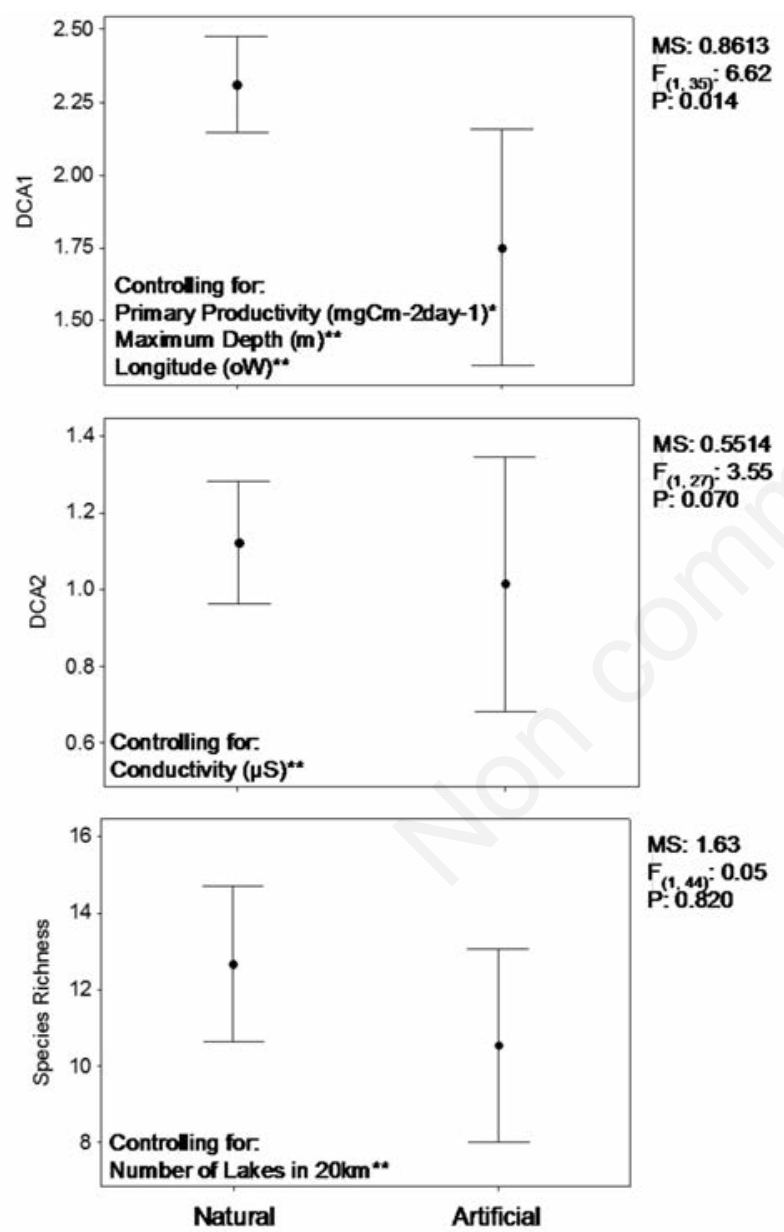

Fig. 7. Results of ANCOVA testing the hypothesis that zooplankton species richness and community composition differ between artificial and natural water bodies, whilst controlling for variation due to significant covariates. Only significant covariates were included in models. $* *$ covariate $\mathrm{P}$ values are significant at $\leq 0.01 ; * \mathrm{P}$ values are significant at $\leq 0.05$. Labels used are: MS, i.e. mean sum of squares, and $\mathrm{F}$, i.e. test value with associated degrees of freedom. pothesis states that when free of predation pressure, larger herbivorous zooplankton will dominate, due to the competitive advantage of being able to more efficiently exploit fine particulate matter. Conversely, under intense predation by planktivorous fish, larger bodied zooplankton are selected against, allowing smaller species to dominate, whilst under moderate predation, populations of larger zooplankton are low enough to allow the co-existence of large and small species. Various studies since have corroborated this hypothesis at least qualitatively (e.g. Hessen et al., 1995; Shurin, 2001; Shurin and Allen, 2001; Vakkilainen et al., 2004; Hülsmann et al., 2005) with Shurin (2001) highlighting the importance of a diverse regional species pool in determining the impact of predation on zooplankton communities. In potential agreement with this, the present study showed that proximity to other water bodies - potential sources of immigrant taxa - was linked with zooplankton species richness.

The occurrences of Ceriodaphnia, Orthocyclops, Holopedium and Eucyclops species were relatively equitable among natural and artificial water bodies, suggesting that these are tolerant of the range of conditions responsible for variation in zooplankton communities between the two types of water body. However, among the water bodies included in the present analysis, five genera were only observed in natural water bodies: Limnocalanus, Senecella, Heterocope, Arctodiaptomus and Aglaodiaptomus. Information on the ecological preferences of these genera is limited due to species-specific variations. However, Heterocope, Limnocalanus and Senecella, along

Tab. 2. Putative drivers of zooplankton species richness and community composition identified from previous large-scale studies of zooplankton in freshwater lakes.

\begin{tabular}{|c|c|c|}
\hline Driver & Species richness & Community composition \\
\hline Conductivity & & $\begin{array}{l}\text { Dodson et al., } 2009 \\
\text { Present study }\end{array}$ \\
\hline Depth & $\begin{array}{c}\text { Dodson, 1992a } \\
\text { O'Brien et al., } 2004 \\
\text { Tavernini et al., } 2009 \\
\text { Present study }\end{array}$ & $\begin{array}{c}\text { Green and Vascotto, } 1978 \\
\text { Korhola, } 1999 \\
\text { Korhola et al., } 2000 \\
\text { Amsinck et al., } 2006 \\
\text { Present study }\end{array}$ \\
\hline Productivity & Dodson, 1992a & $\begin{array}{l}\text { Dodson et al., } 2009 \\
\text { Present study }\end{array}$ \\
\hline Geographic location & $\begin{array}{l}\text { Dodson, 1992a } \\
\text { Present study }\end{array}$ & $\begin{array}{l}\text { Shaw and Kelso, } 1992 \\
\text { Dodson et al., } 2009 \\
\text { Present study }\end{array}$ \\
\hline Surface area & $\begin{array}{c}\text { Dodson, 1992a } \\
\text { O'Brien et al., } 2004 \\
\text { Karatayev et al., } 2005 \\
\text { Tavernini et al., } 2009 \\
\text { Dodson et al., } 2009 \\
\text { Present study }\end{array}$ & $\begin{array}{c}\text { Shaw and Kelso, } 1992 \\
\text { Dodson et al., } 2009\end{array}$ \\
\hline
\end{tabular}


with Leptodiaptomus, which occurred significantly more often in natural water bodies, all contain at least some species which show a preference for deep water (Tab. 3), consistent with relatively low scores of each on at least one of the DCA axes. Acanthocyclops and Cyclops also occurred more frequently in natural water bodies and are relatively cool water species (Tab. 3). Conversely, species of the genus Thermocyclops, which occurred more often in artificial water bodies, tend to show a tolerance to a range of water temperatures, with some exclusively warm water species. Although the representation of artificial lakes was limited, these observations could suggest that the natural lakes in this study provided conditions favourable to deeper and cooler water species. This would be consistent with the use of artificial mixing in artificial water bodies, which destratifies the water column, likely removing deep, cool refugia.

In contrast to natural water bodies, none of the genera occurred exclusively in artificial water bodies. In other words, while all taxa found in artificial water bodies are also found in natural lakes, the opposite is not true, suggesting that certain niches are lacking in the artificial lakes tested. These results should be considered with caution and require further investigation due to the limited representation of artificial water bodies in the present metaanalysis, but could suggest that management practices in artificial water bodies reduce the number of specific niches available for more specialist taxa.

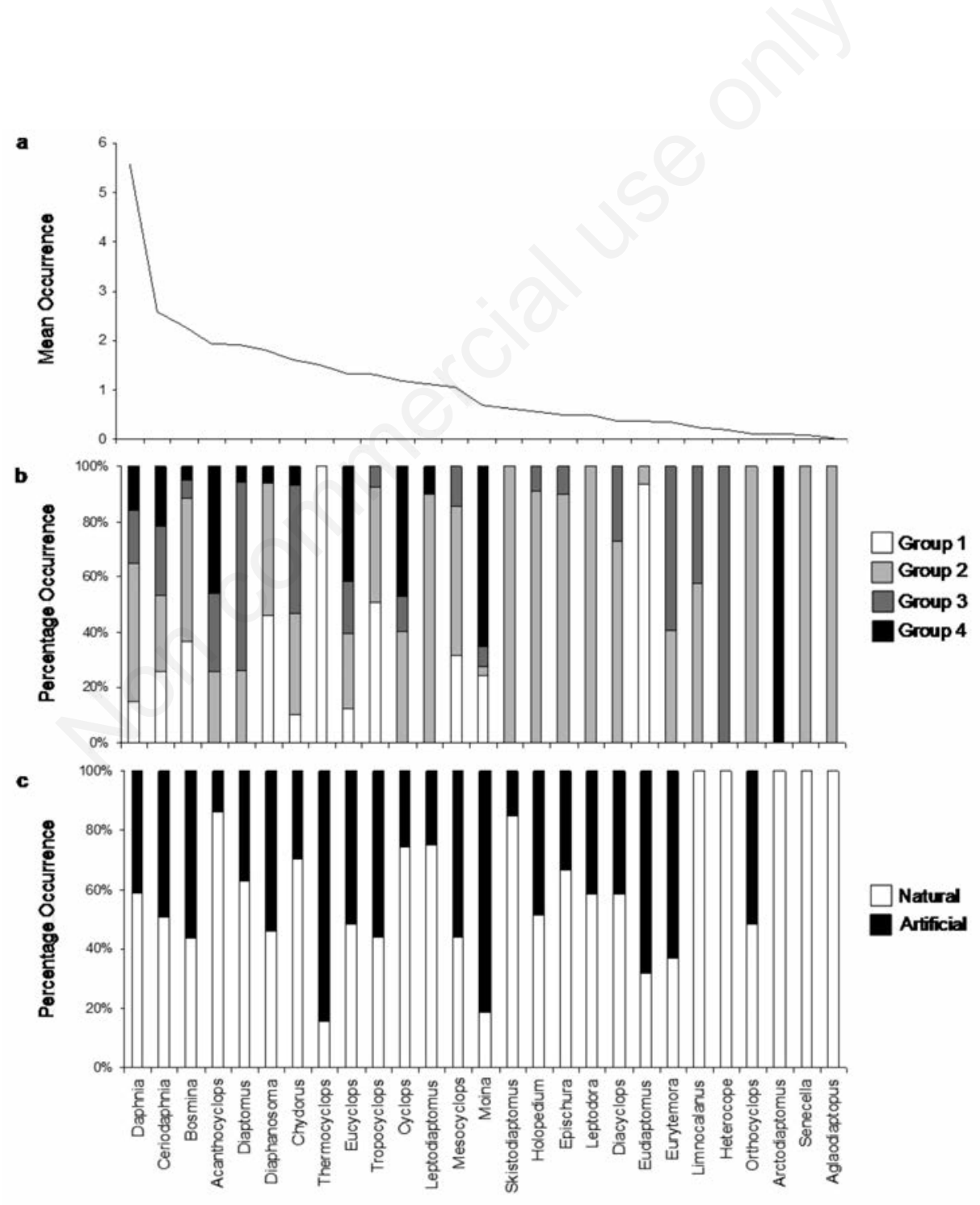

Fig. 8. Occurrence of 29 zooplankton genera recorded in 79 lakes: a) shows mean total occurrence of each genus among all water bodies; b) identifies percentage occurrence of genera in each TWINSPAN group of water bodies; c) shows percentage occurrence of genera in natural and artificial water bodies. 
Tab. 3. Zooplankton genera that occurred significantly more frequently (or exclusively) in either artificial or natural water bodies in a meta-analysis of global water bodies, with notes on their ecology.

\begin{tabular}{lccc}
\hline Genus & Water body preference & Ecology & References \\
\hline Acanthocyclops & Natural & Cyclopoid copepod & Thorp and Covich, 2001 \\
& Relatively cool water genus \\
Large-bodied & Wissinger et al., 1999
\end{tabular}

Widely distributed across North America and Europe

\begin{tabular}{lcc}
\hline Aglaodiaptomus & Calanoid copepod & Taylor et al., 1999 \\
& Mostly herbivorous \\
& Relatively large-bodied & \\
& Absent from man-made impoundments in Carolina (USA)
\end{tabular}

\begin{tabular}{lll}
\hline Arctodiaptomus & Calanoid copepod & Jiménez-Melero et al., 2007 \\
& Salinity tolerance & Tolerance of a range of temperatures
\end{tabular}

\begin{tabular}{lccc}
\hline Chydorus & $\begin{array}{c}\text { Natural } \\
\text { Herbivorous } \\
\text { Small-bodied }\end{array}$ & Cladoceran & Dodson, 1992a \\
\hline Cyclops & Natural & $\begin{array}{c}\text { Cyclopoid copepod } \\
\text { Zooplanktivorous } \\
\text { Large-bodied }\end{array}$ & Thorp and Covich, 2001 \\
& Relatively cool-water species & Calanoid copepod \\
Epischura & Natural & $\begin{array}{c}\text { Zooplanktivorous/omnivorous } \\
\text { Large-bodied }\end{array}$ & $\begin{array}{c}\text { Chow-Fraser and Maly, 1988 } \\
\text { Thorp and Covich, 2001 } \\
\text { Lampert and Sömmer, 2007 }\end{array}$ \\
\hline
\end{tabular}

\begin{tabular}{llll}
\hline Eudiaptomus & Artificial & $\begin{array}{c}\text { Calanoid copepod } \\
\text { Herbivorous }\end{array}$ & Lampert and Sömmer, 2007 \\
\hline Heterocope & Natural (exclusively) & $\begin{array}{l}\text { Calanoid copepod } \\
\text { Zooplanktivorous }\end{array}$ & Lueke and O’Brien, 1981
\end{tabular}

At least some deep water species

Absent from very shallow water bodies

\begin{tabular}{|c|c|c|c|}
\hline Leptodiaptomus & Natural & $\begin{array}{c}\text { Calanoid copepod } \\
\text { Some saline tolerance } \\
\text { Some preference for deeper habitats }\end{array}$ & Montiel-Martínez et al., 2008 \\
\hline Limnocalanus & Natural (exclusively) & $\begin{array}{c}\text { Calanoid copepod } \\
\text { Carnivorous } \\
\text { Tolerant of low temperatures } \\
\text { Preference for deeper habitats }\end{array}$ & $\begin{array}{c}\text { Scourfield and Harding, } 1994 \\
\text { Thorp and Covich, } 2001 \\
\text { Gurney, 1933b }\end{array}$ \\
\hline
\end{tabular}

\begin{tabular}{|c|c|c|c|}
\hline Moina & Artificial & $\begin{array}{c}\text { Cladoceran } \\
\text { Produce both males and females from ephippial eggs } \\
\text { Relatively high salinity tolerance } \\
\text { Produce swarms } \\
\text { Common in temporary ponds and pools }\end{array}$ & Thorp and Covich, 2001 \\
\hline Senecella & Natural (exclusively) & $\begin{array}{c}\text { Calanoid copepod } \\
\text { Herbivorous } \\
\text { Some saline tolerant species } \\
\text { Some preference for deeper habitats }\end{array}$ & Vyshkvartzeva, 1994 \\
\hline Skistodiaptomus & Natural & $\begin{array}{l}\text { Calanoid copepod } \\
\text { Omnivorous }\end{array}$ & Balcer et al., 1984 \\
\hline Thermocyclops & Artificial & $\begin{array}{l}\text { Cyclopoid copepod } \\
\text { Tolerant of higher temperatures }\end{array}$ & $\begin{array}{l}\text { Maier, } 1989 \\
\text { Maier, } 1993\end{array}$ \\
\hline
\end{tabular}




\section{CONCLUSIONS}

In the present study we came to the conclusion that, while there was an effect of longitude on zooplankton community composition among the water bodies studied here, there also appeared to be differences in the scale at which the processes linked with changes in species richness and composition acted. Proximity to a larger number of lakes was found to be important in maintaining species richness, likely through increased immigration from regional source populations. Community composition however, was linked with intrinsic factors such as depth, productivity and conductivity, acting at the local scale, and depending on whether a water body was man-made or naturally formed. These results are among the first to suggest that zooplankton communities in artificial water bodies may be structured significantly differently from those in naturally formed lakes. Intrinsic local factors appear to create conditions favourable to more specialist taxa in natural water bodies. Whether these observations are the result of variations in bottom-up or top-down influences between artificial and natural lakes is unknown and undoubtedly complex to determine. Nevertheless, they highlight the potential for variations at higher trophic levels, as well as bottom-up effects such as water chemistry, that require future investigation.

\section{ACKNOWLEDGMENTS}

The authors thank the Cardiff Harbour Authority (CHA), who provided funding for this work as part of an in-depth study of an artificial urban lake in Cardiff, UK.

\section{REFERENCES}

Amsinck SL, Strzelczak A, Bjerring R, Landkildehus F, Lauridsen T, Christoffersen K, Jeppesen E, 2006. Lake depth rather than fish planktivory determines cladoceran community structure in Faroese lakes - evidence from contemporary data and sediments. Freshwater Biol. 51:2124-2142.

Antenucci JP, Ghagouani A, Burford MA, Romero JR, 2005. The long-term effect of artificial destratification on phytoplankton species composition in a subtropical reservoir. Freshwater Biol. 50:1081-1093.

Balcer MD, Korda NL, Dodson SI, 1984. Zooplankton of Great Lakes: a guide to the identification and ecology of the common crustacean species. The University of Wisconsin Press, Madison, WI, USA.

Barnett AJ, Beisner BE, 2007. Zooplankton biodiversity and lake trophic state: explanations invoking resource abundance and distribution. Ecology 88:1675-1686.

Baxter RM, Glaude PG, 1980. Environmental effects of dams and impoundments in Canada: experience and prospects. Can. B. Fish. Aquat. Sci. 205:1-34.

Becker A, Herschel A, Wilhelm C, 2006. Biological effects of incomplete stratification of hypertrophic freshwater reservoir. Hydrobiologia 559:85-100.

Brooks JL, Dodson SI, 1965. Predation, body size, and composition of plankton. Science 150:28-35.
Burford MA, O’Donohue MJ, 2006. A comparison of phytoplankton community assemblages in artificially and naturally mixed subtropical water reservoir. Freshwater Biol. 51:973-982.

Chase JM, Ryberg WA, 2004. Connectivity, scale dependence, and the productivity-diversity relationship. Ecol. Lett. 7:676-683.

Chow-Fraser P, Maly EJ, 1988. Aspects of mating, reproduction, and co-occurrence in three freshwater calanoid copepods. Freshwater Biol. 19:95-108.

Cowell BC, Dawes CJ, Gardiner WE, Scheda SM, 1987. The influence of whole lake aeration on the limnology of a hypereutrophic lake in central Florida. Hydrobiologia 148:324.

De Mérona B, Medes Dos Santos G, Gonçalves De Almeida R, 2001. Short-term effects of Tucuruí Dam (Amazonia, Brazil) on the trophic organization of fish communities. Environ. Biol. Fish. 60:375-392.

Dodson SI, 1992a. Predicting crustacean zooplankton species richness. Limnol. Oceanogr. 37:848-856.

Dodson SI, 1992b. Supplementary material: data base and literature for Predicting crustacean zooplankton species richness. Department of Zoology, University of Wisconsin ed., Madison, WI, USA: 34 pp.

Dodson SI, Arnott SE, Cottingham KL, 2000. The relationship in lake communities between primary productivity and species richness. Ecology 81:2662-2679.

Dodson SI, Everhart WR, Jandl AK, Krauskopf SJ, 2006. Effects of watershed land use and lake age on zooplankton species richness. Hydrobiologia 579:393-399.

Dodson SI, Newman AL, Will-Wolf S, Alexander ML, Woodford WP, Van Egeren S, 2009. The relationship between zooplankton community structure and lake characteristics in temperate lakes (Northern Wisconsin, USA). J. Plankton Res. 31:93-100.

Forbes AE, Chase JM, 2002. The role of habitat connectivity and landscape geometry in experimental zooplankton communities. Oikos 96:433-440.

Fryer G, 1985. Crustacean diversity in relation to the size of water bodies: some facts and problems. Freshwater Biol. 15:347-361.

Gaston KJ, Spicer JI, 2004. Biodiversity: an introduction. $2^{\text {nd }}$ ed. Blackwell Science, Oxford, UK.

Gliwicz ZM, Lampert W, 1990. Food thresholds in Daphnia species in the absence and presence of blue-green filaments. Ecology 71:691-702.

Green RH, Vascotto GL, 1978. A method for the analysis of environmental factors controlling patterns of species composition in aquatic communities. Water Res.12:583-590.

Gurney R, 1933a. British Freshwater Copepoda, I. Ray Society, London, UK.

Gurney R, 1933b. British Freshwater Copepoda, III. Ray Society, London, UK.

Halvorsen G, Gullestad N, 1976. Freshwater Crustacea from some areas of Svalbard. Arch. Hydrobiol. 78:383-395.

Hawkins PR, Griffiths DJ, 1993. Artificial destratification of a small tropical reservoir - effects upon the phytoplankton. Hydrobiologia 254:169-181.

Hessen DO, Faafeng BA, Andersen T, 1995. Replacement of herbivore zooplankton species along gradients of ecosystem 
productivity and fish predation pressure. Can. J. Fish. Aquat. Sci. 52:733-742.

Hessen DO, Faafeng BA, Smoth VH, Bakkestuen V, Walseng B, 2006. Extrinsic and intrinsic controls of zooplankton diversity in lakes. Ecology 87:433-443.

Hill MO, Šmilauer O, 2005. TWINSPAN for Windows version 2.3. Centre for Ecology and Hydrology and University of South Bohemia ed., Huntingdon (UK) and Ceské Budejovice (Czech Republic): 29 pp.

Hobæk A, Manca M, Andersen T, 2002. Factors influencing species richness in lacustrine zooplankton. Acta Oecol. 23:155-163.

Hoffmann MD, Dodson SI, 2005. Land use, primary productivity and lake areas as descriptors of zooplankton diversity. Ecology 86:255-261.

Holland TA, Jenkins DG, 1998. Comparison of processes regulating zooplankton assemblages in new freshwater pools. Hydrobiologia 387/388:207-214.

Hülsmann S, Rinke K, Mooij WM, 2005. A quantitative test of the size efficiency hypothesis by means of a physiologically structured model. Oikos 110:43-54.

Jiménez-Melero R, Parra G, Souissi S, Guerrero F, 2007. Postembryonic developmental plasticity of Arctodiaptomus salinus (Copepoda: Calanoida) at different temperatures. J. Plankton Res. 29:553-567.

Karatayev AY, Burlakova LE, Dodson SI, 2005. Community analysis of Belarusian lakes: relationship of species diversity to morphology, hydrology and land use. J. Plankton Res. 27:1045-1053.

Korhola A, 1999. Distribution patterns of Cladocera in subarctic Fennoscanadian lakes and their potential in environmental reconstruction. Ecography 22:357-373.

Korhola A, Orlander H, Blom T, 2000. Cladoceran and chironomid assemblages as quantitative indicators of water depth in subarctic Fennoscanadian lakes. J. Paleolimnol. 24:4354.

Lampert W, Sömmer U, 2007. Limnoecology. Oxford University Press, Oxford, UK.

Lewis DM, Elliott A, Brookes JD, Irish AE, Lambert MF, Reynolds CS, 2003. Modelling the effects of artificial mixing and copper sulphate dosing on phytoplankton in an Australian reservoir. Lakes Reserv. Res. Manage. 8:31-40.

Lueke C, O'Brien WJ, 1981. Phototoxicity and fish predation: selective factors in color morphs in Heterocope. Limnol. Oceanogr. 26:454-460.

MacArthur RH, Wilson EO, 1967. The theory of island biogeography. Princeton University Press, NJ, USA.

Maier G, 1989. The seasonal cycle of Thermocyclops crassus (Fischer 1853) (Copepoda: Cyclopoida) in a shallow, eutrophic lake. Hydrobiologia 178:43-58.

Maier G, 1993. An example of niche partitioning in three coexisting freshwater cyclopoid copepods. J. Plankton Res. 15:1097-1102.

Matsumura-Tundisi T, Tundisi JG, 2002. Zooplankton diversity change in man-made lakes. Case study of the Barra Bonita Reservoir, SP, Brazil, p. 212-215. In: Proc. $4^{\text {th }}$ International Conference on Reservoir Limnology of Water. Ceské Budejovice, Czech Republic.

Merrix F, 2009. Zooplankton in the newly formed Cardiff Bay. PhD Thesis, Cardiff University ed., Cardiff, UK.
Montiel-Martínez A, Ciros-Pérez J, Ortega-Mayagoita E, ElíasGutiérrez M, 2008. Morphological, ecological, reproductive and molecular evidence for Leptodiaptomus garciai (Osorio-Tafall 1942) as a valid endemic species. J. Plankton Res. 30:1079-1093.

O'Brien WJ, Barfield M, Bettez ND, Gettel GM, Hershey AE, McDonald ME, Miller MC, Mooers H, Pastor J, Richards C, Schuldt J, 2004. Physical, chemical, and biotic effects on arctic zooplankton communities and diversity. Limnol. Oceanogr. 49:1250-1261.

Osenberg CW, Sarnelle O, Cooper SD, Holt RD, 1999. Resolving ecological questions through meta-analysis: Goals, metrics, and models. Ecology 80:1105-1117.

Richman S, Dodson SI, 1983. The effect of food quality on feeding and respiration by Daphnia and Diaptomus. Limnol. Oceanogr. 28:948-956.

Riggs MR, Haroldson KJ, Hanson MA, 2008. Analysis of covariance models for data from observational field studies. J. Wildlife Manage. 72:34-43.

Scheffer M, Rinaldi S, Huisman J, Weissing FJ, 2003. Why plankton communities have no equilibrium: solutions to the paradox. Hydrobiologia 419:9-18.

Scourfield DJ, Harding JP, 1994. A key to the species of freshwater cladocera. Freshwater Biological Association ed., Windermere, UK.

Shaw MA, Kelso JRM, 1992. Environmental factors influencing zooplankton species composition of lakes in north-central Ontario, Canada. Hydrobiologia 241:141-154.

Shurin JB, 2001. Interactive effects of predation and dispersal on zooplankton communities. Ecology 82:3404-3416.

Shurin JB, Allen EG, 2001. Effects of competition, predation, and dispersal on species richness at local and regional scales. Am. Nat. 158:624-637.

Shurin JB, Arnott SE, Hillebrand H, Langmuir A, Pinel-Alloul B, Winder M, Yan ND, 2007. Diversity-stability relationship varies with latitude in zooplankton. Ecol. Lett. 10:127-134.

Smith VH, 1983. Low nitrogen to phosphorous ratios favour dominance by blue-green algae in lake phytoplankton. Science 221:669-671.

Sömmer UZ, Gliwicz M, Lampert W, Duncan A, 1986. The PEG model of seasonal succession of planktonic events in fresh water. Arch. Hydrobiol. 106:433-471.

Speckman SG, Piatt JF, Minte-Vera CV, Parrish JK, 2005. Parallel structure among environmental gradients and three trophic levels in a subarctic estuary. Prog. Oceanogr. 66:2565.

Strøm KM, 1946. The ecological niche. Nature 157:375.

Tavernini S, Primicerio R, Rossetti G, 2009. Zooplankton assembly in mountain lentic waters is primarily driven by local processes. Acta Oecol. 35:22-31.

Taylor BE, Leeper DA, McClure MA, DeBiase AE, 1999. Carolina Bays: ecology of aquatic invertebrates and perspectives on conservation, p. 167-196. In: D.P. Batzer, R.B. Rader, S.A. Wissinger (eds). Invertebrates in freshwater wetlands of north America: ecology and management. John Wiley and Sons, New York, NY, USA.

Thackeray SJ, 2007. Crustacean zooplankton species richness and productivity: to what extent do the conclusions depend on the choice of metrics used? Oikos 116:614-628.

Thorp JH, Covich AP, 2001. Ecology and classification of north 
American freshwater invertebrates. Academic Press, London, UK.

Vakkilainen K, Kairesalo T, Heitala J, Balaya DM, Bécares E, Van de Bund WJ, Van Donk E, Fernández-Aláez M, Gyllström M, Hansson LA, Miracle MR, Moss B, Romo S, Rueda J, Stephen D, 2004. Response of zooplankton to nutrient enrichment and fish in shallow lakes: a pan-European mesocosm experiment. Freshwater Biol. 49:1619-1632.

Vyshkvartzeva NV, 1994. Senecella siberica n. sp. and the position of the genus Senecella in Calanoida classification. Hydrobiologia 292/293:113-121.
Watson SB, McCauley E, Downing JA, 1997. Patterns in phytoplankton taxonomic composition across temperate lakes of differing nutrient status. Limnol. Oceanogr. 42:487-495.

Wissinger SA, Bohonak AJ, Whiteman HH, Brown WS, 1999. Subalpine wetlands in Colorado: habitat permanence, salamander predation, and invertebrate communities, p. 757790. In: D.P. Batzer, R.B. Rader, S.A. Wissinger (eds.). Invertebrates in freshwater wetlands of north America: ecology and management. John Wiley and Sons, New York, NY, USA. 